\title{
Research on the Application of Cloud Resources in Universities under the Background of Big Data
}

\author{
LIU Xiong \\ Wuhan Textile University, Wuhan, 430073, China \\ email: Ix@wtu.edu.cn
}

Key words: big data; cloud resources; cloud computing; application

\begin{abstract}
With the development of information technology, all kinds of data information resources show an explosive growth trend, the number of data information tends to increase, the diversity of information types also tends to increase, then the information field has ushered in the time of big data. In the background of big data which contains large amount of information and a wide and diverse variety of information, college teaching services and data utilization will have a significant change, and thus bring new opportunities. Along with the emergence of cloud computing, as for college data resources integration, big data and cloud computing could be combined together to provide data support for teachers' teaching, student learning and the management of the university.
\end{abstract}

\section{Introduction}

"Big data" is the most popular word which follows the "Web2.0", "data mining" and "cloud computing" in IT industry in the past two years. Revolution of big data keeps going on which takes Hardtop Apache as the center, some business organization such as IBM、EMC、Oracle、 VMware and Microsoft have seen the commercial value of this revolution, they are eager to invest the research of big data, and they hope to occupy the initiative in this market, they develop some products such as Biglnisights which are based on the cloud computing platform. Big data technology can help users to quickly find the required resources in the vast ocean of data. Facing these advantages of big data, the education sector has also set off a boom of research on big data. In "2013NMC horizon report (Higher Education Edition)", there is a predictive thought which point that "Big data and learning analysis" will be the main technology in the next 2 to 3 years.[1] In the era of big data, the focus of today's education field is how to improve the processing capability of growing education resources and look for new data calculation method. Besides, to solve the above problems, we must have rational understanding of large data.

\section{Integration and utilization of cloud resources in Colleges and Universities in the big data era}

A. To provide an opportunity for the management and development of university library

For the library profession, the emergence of cloud computing has changed the traditional library service mode and application of cloud computing storage, management and other related technology. These can provide network utilization for readers; as a result it changes the window service mode of the traditional library in a large extent. With the help of cloud computing, the library can step into the network and the digital application stage, so as to establish the college digital library which use cloud resources as the main mode. [2] In addition, with the data analysis and mining functions, large data can analyze and induce all kinds of information in the cloud storage, figure out students' demand of borrowing books and structure of students' knowledge level. In this way, library managers will have a better reference when they are making decision. According to the research of borrowers and interaction between readers and library service, with the help of prediction and analysis of big data, we should have forethought in the late development of library; as for the collections of the library information data, we can also establish related risk assessment model through large data. 


\section{B. To lead users to learn more easily}

The combination of big data and cloud technology makes the application of education resources break through the original significance of application pattern, so that teachers and students not only can share the storage of education resources in the cloud server and have the analysis and mining of all kinds of data. [3] After that, they can find the hidden and underlying data information, plus, they can provide the most reasonable strategies and programs for teachers and students. Teachers can analyze students' non structured data such as learning behavior and learning interests through the big data technology, so teachers can make predictions and make decisions in time, guide students to learn and make assessment of the courses by using data analysis techniques for adjusting the training program in time. Big data technology can be used to analyze the behaviors of students for a certain period of time, such as Internet, extra-curricular study. It can also be used to predict what will occur in the next period, so the most suitable decisions for the healthy developments of students can be made as soon as possible through these predictions. Besides, based on data analysis technology, students can have recommended learning trajectory, and then they can carry out adaptive learning and self-directed learning.

C. To provide reference for the management of colleges and universities

The traditional data analysis is based on the group survey, which does not have a high precision of data. After entering the era of big data, more overall and accurate information reference can be provide for decision making with the aid of analysis function of big data. Therefore, manager and decision maker can have a more accurate grasp of market, products and consumer groups. From the perspective of high university, through the use of big data and cloud information analysis and processing technology, the development condition and the latter trend of high university can be simulated; the management and decision can be verified with related data information so as to avoid the risk of decision making. [4] Moreover, through the technology of big data, higher education can achieve the unity of quality and equity, and with the penetration of big data technology in every department of high university, teaching and management effects in high universities can be further verified, which can help to implement the reform of colleges and universities.

\section{The principle and process of data processing and service in the application of cloud resources in big data era}

\section{A. Data processing in big data era}

Cloud computing has solved the problem of data storage and computing to a great extent. Therefore, all colleges and universities have invested funds to build a cloud based teaching environment to improve the utilization of educational resources. But the analysis of the data is still dependent on the simple relational database, utilization of this simple analysis method for analyzing data, and querying often needs a lot of time, manpower, material resources. And it has low efficiency. Faced with these problems, the era of big data proposed to use Hadoop technology including memory retrieval technology, the technology of real time data response to analyze a large number of educational resources. [5] This method improves the speed and efficiency of data analysis by constructing resources- processing platform which is based on cloud computing, and by the management of Map Reduce programming model. In the era of big data, data mining still adopts cloud computing, this kind of technology can analyze and mine those large, incomplete, fuzzy education resources which are stored in the cloud server, these hidden and unknown information and data are very valuable to teachers and students. The analysis and mining can provide forewarning and help, at the same time, the library can also analyze the reader's learning behavior, reading behavior, hobbies based on the reader's lending books information and put forward a new service plan or strategy. Its data processing platform is shown in figure 1. 


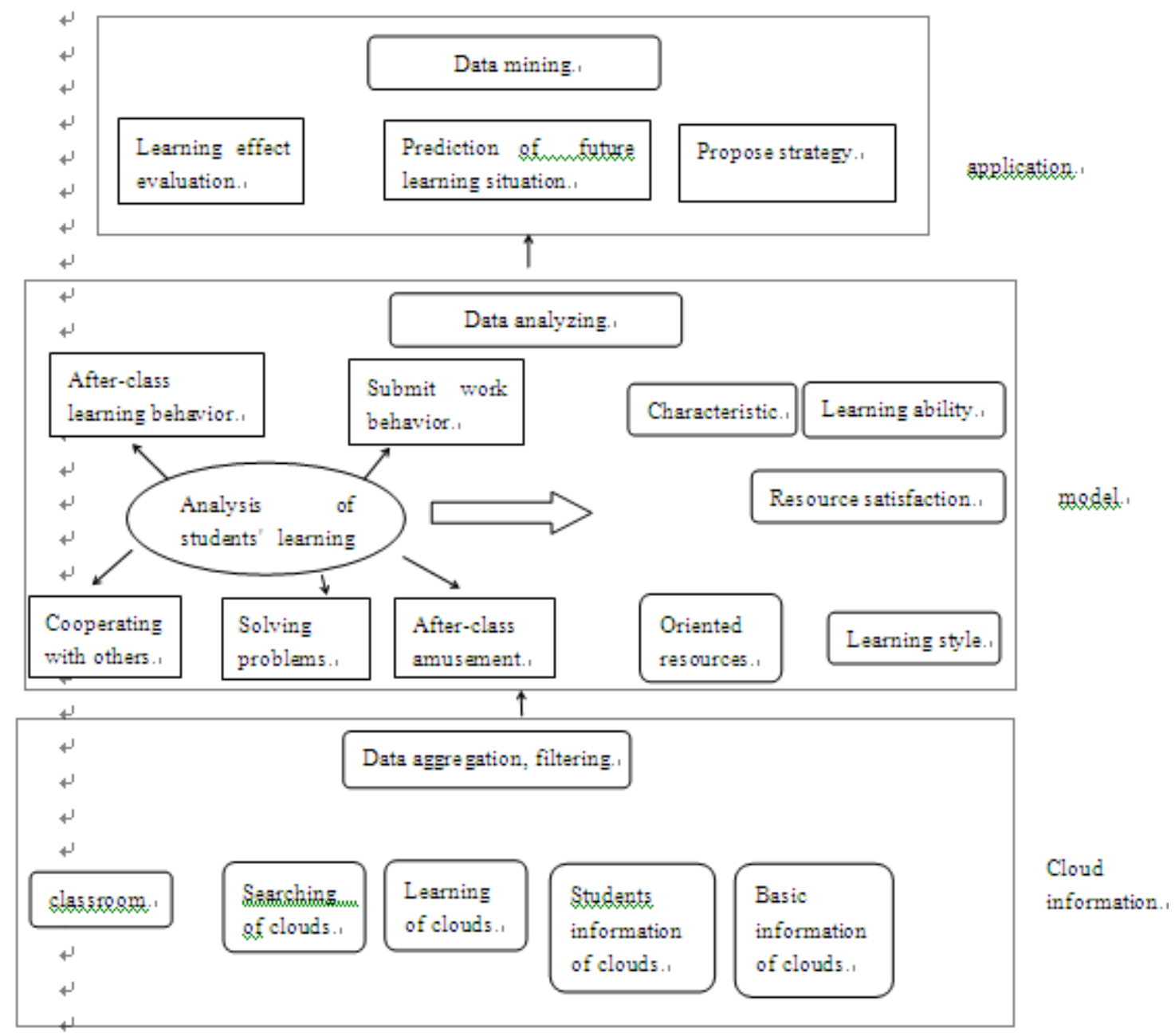

Figure 1 Large data processing platform based on cloud data

B. Educational resource services in the era of data

Under the background of big data, the university education resources will continue to change in the way of service, the pattern and so on. First, in the context of large data, for users, resource services provided by the education only guide them to pay attention to its final results and do not have to know its internal reasons. The ultimate goal of resource service in colleges and universities is to provide users with the fastest, most timely and accurate service, With regard to the data processing center, it only needs that big data technology is applied to analyze and mine various pieces of data in order to judge whether the teaching methods can effect teachers' teaching or students' learning. If the effect is obvious, then the decision maker only needs to decide whether to use this kind of teaching method, not to investigate the reason which makes the efficiency fluctuate. Secondly, in the era of big data, resources services will be more active, more close to the actual needs of users. With the acceleration of the information age and in the context of digital campus, all colleges and universities have to integrate the resources of the system in order to maximize the use of resources. In this way, college students can not only make the best possible use of resources, but also can participate in interactive work such as resource platform construction, service evaluation and so on. On the other hand, the system can collect the "traces" left on the platform by the users in order to grasp the users' requirements of various resources dynamically, and to meet the needs of users in a timely manner. This allows users approve resources provided by the resource center, and the resource center will greatly enhance the awareness of active service because of users' approval. 


\section{The development trend of the application of cloud resources in the big data era}

\section{A. Moving forward in the direction of students' life-long learning}

In the era of big data, university information center will not only deal with simple relational data, but also record the data about students' unstructured behaviors (browsing, downloading) which are leaved in the platform .And the task of data processing center is analyzing and mining the data and eventually presenting it to students in a data representation mode. In this way, students can understand their own learning frequency and type, learning situation in a period of time. At the same time, students can have tailored learning plan provided by the data processing center. Therefore, this will enable students develop from previous "fuzzy" learning to "aware "learning, and truly realize life-long learning.

B. Moving forward in the direction of changing the traditional teaching and learning mode to communicating mode in the classroom

In the future of the big data environment, the classroom will be based on the exchange of learning. In the traditional class, teacher mainly acts as the role of teaching, not a member of communication between students. It is very difficult to achieve very good teaching effect in this way. However, in the era of big data, with the aid of data technology, teachers can make learning video which includes the knowledge students don't know as more as possible after they understand the basic situation of the students. And students can view the video purposefully and selectively. Afterwards, students will go back to actual classroom, interact with teachers and students. In this interactive class, students will be more active and have higher efficiency.

C. Moving forward in the direction of more efficient, safer classroom management

The management of a traditional laboratory or multimedia classroom is usually by one manager who manages a room or a few rooms. However, this kind of management does not have high efficiency, and waste human resources in colleges and universities. In the era of big data, colleges and universities can store be computer labs or multimedia classroom information into the data center. At the same time, universities can use big data technology to analyze the parameters of different campuses, different classes, different classes, different periods and different teaching equipment in the classroom. After that, universities can have a future trend prediction of some devices of some classrooms at a certain time trough the feedback of the data, to judge whether the device is broke down or the device can withstand high load operation, etc. This allows the managers to replace those broken devices in advance in order to avoid large losses. This will greatly improve equipment utilization rate, and in this trend only a few administrators in equipment monitoring center of campus are needed for all computer room monitoring. So it can greatly save the manpower, material and financial resources.

\section{Conclusion}

Data is being mature and developed with the development of mobile Internet and cloud computing technology. It has been widely concerned by the IT industry and academia. Its appearance finds a bigger stage for practical application of cloud computing. Through the use of super powerful data storage and data calculation ability of cloud computing, big data can the can be more convenient to handle vast amounts of information. It provides users with a more convenient and faster service; it will be the key for the humanity to move towards the "wisdom". As far as university is concerned, the information resources are gradually complex, large-scale. With the aid of big data and cloud computing technology, universities can establish the cloud resource database which can provide detailed scientific guidance for teaching, learning and decision-making.

\section{References}

[1] El Ahrache,S.I,Badir,H,Tabaa,Y.et al.Massive Open Online Courses:A New Dawn for Higher Education?. International Journal on Computer Science and Engineering . 2013 
[2] Vineet Guhal,Manish Shrivastava.Review of Information Authentication in Mobile Cloud over SaaS \& PaaS Layers. International Journal of Advanced Computer Research . 2013

[3] M. Samir Abou El-Seoud,Hosam F. El-Sofany,Islam A. T. F. Taj-Eddin,Ann Nosseir,Mahmoud M. El-Khouly.Implementation of Web-Based Education in Egypt through CloudComputing Technologies and Its Effect on Higher Education. . 2013

[4] Bodenreider O.The Unified Medical Language System (UMLS): integrating biomedical terminology. Nucleic Acids Research . 2004

[5] X. Zhou,Z. Wu,A. Tin, et al.Ontology Development for Unified Traditional Chinese Medical. Journal of Artificial Intelligence in Medicine . 2004 